\title{
Daily home gardening improved survival for older people with mobility limitations: an I I-year follow-up study in Taiwan
}

\author{
Chhian Hūi Lêng ${ }^{1,2}$ \\ Jung-Der Wang ${ }^{3-5}$
}

'Institute of Allied Health Sciences, College of Medicine, National Cheng Kung University, Tainan, ${ }^{2}$ School of Medical Sociology and Social Work, Chung Shan Medical University, Taichung, ${ }^{3}$ Department of Public Health, College of Medicine, ${ }^{4}$ Department of Occupational and Environmental Medicine, ${ }^{5}$ Department of Internal Medicine, National Cheng Kung University Hospital, Tainan, Taiwan
Correspondence: Jung-Der Wang Department of Public Health, College of Medicine, National Cheng Kung University, I University Road, Tainan 70I, Taiwan

Tel +88662353535 ext 5600

Fax +886 62359033

Email jdwang121@gmail.com
This article was published in the following Dove Press journal:

Clinical Interventions in Aging

15 July 2016

Number of times this article has been viewed
Aims: To test the hypothesis that gardening is beneficial for survival after taking time-dependent comorbidities, mobility, and depression into account in a longitudinal middle-aged (50-64 years) and older ( $\geq 65$ years) cohort in Taiwan.

Methods: The cohort contained 5,058 nationally sampled adults $\geq 50$ years old from the Taiwan Longitudinal Study on Aging (1996-2007). Gardening was defined as growing flowers, gardening, or cultivating potted plants for pleasure with five different frequencies. We calculated hazard ratios for the mortality risks of gardening and adjusted the analysis for socioeconomic status, health behaviors and conditions, depression, mobility limitations, and comorbidities. Survival models also examined time-dependent effects and risks in each stratum contingent upon baseline mobility and depression. Sensitivity analyses used imputation methods for missing values.

Results: Daily home gardening was associated with a high survival rate (hazard ratio: 0.82; 95\% confidence interval: $0.71-0.94$ ). The benefits were robust for those with mobility limitations, but without depression at baseline (hazard ratio: $0.64,95 \%$ confidence interval: $0.48-0.87$ ) when adjusted for time-dependent comorbidities, mobility limitations, and depression. Chronic or relapsed depression weakened the protection of gardening. For those without mobility limitations and not depressed at baseline, gardening had no effect. Sensitivity analyses using different imputation methods yielded similar results and corroborated the hypothesis.

Conclusion: Daily gardening for pleasure was associated with reduced mortality for Taiwanese $>50$ years old with mobility limitations but without depression.

Keywords: gardening, mortality, leisure activity, survival, epidemiology

\section{Introduction}

Physical inactivity is the fourth leading risk factor of mortality. ${ }^{1}$ For inactive older adults ( $\geq 65$ years old), a prescribed volume of physical activity ${ }^{2}$ might be a barrier to long-term adherence. Gardening is an especially feasible leisure time activity in Taiwan because plants grow all year round in its tropical marine climate. However, on this island with its high population density, most households do not have land and gardeners usually manage houseplants by themselves at or near their homes (Figure 1). Growing potted plants requires neither owning land nor much physical effort. It is thus of interest to examine whether home gardening without much physical exertion yields a beneficial effect on survival similar to that reported for the Danish Diet, Cancer and Health cohort, ${ }^{3}$ a New Haven elderly cohort, ${ }^{4}$ and a Finnish cohort in $1980 .{ }^{5}$ It is also possible that there are some reservations about the benefits, as in the Whitehall II cohort study. ${ }^{6}$ 

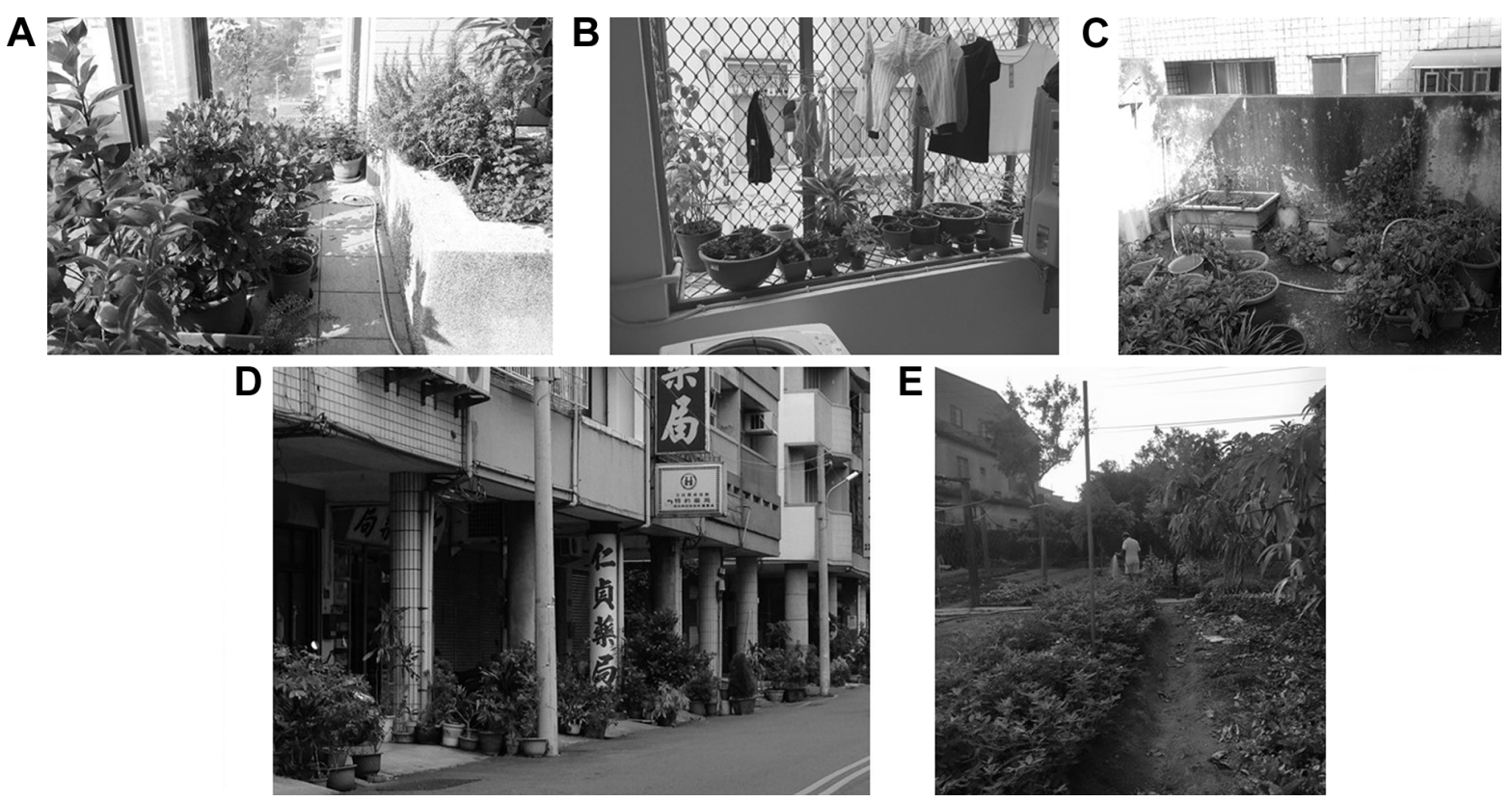

Figure I Common gardening types in households without landscaping gardens in Taiwan.

Notes: (A) on the sunporch; (B) on the sunporch; (C) on the roof; (D) at the front door; (E) a vegetable garden near home. Courtesy of Andy Chang, Chiu Shan Chang, Miyah Chen, Claire Hong, and Ben Yu (by last name order).

Home gardeners are usually more solitary than community gardeners. ${ }^{7}$ Although gardening as a leisure activity or a versatile therapeutic medium has a long history, its temporal health effects might not be directly evidenced by cross-sectional data that reflect a person's current health condition. Therefore, we considered temporality and used time-dependent covariates to construct our survival models. Mobility limitations and comorbidities easily interrupt and stop leisure gardening; we examined these covariates as either cross-sectional or time-dependent. Because indoor plants ${ }^{8}$ and gardening 9 seem to psychologically and physically benefit many people, we examined whether self-reported depression interfered with the potential temporal health effects of gardening in our survival models.

The present study, which followed-up a national representative cohort $\geq 50$ years old, and which was linked to Taiwan's National Mortality Registry, examined the longterm effects of gardening on all-cause mortality. We used time-dependent models to examine, after adjusting for current mobility, depression, comorbidities, and some baseline potential confounders, whether leisure gardening had any long-term effect on all-cause mortality.

\section{Methods}

\section{Participants}

The study was approved by the Human Experiment and Ethics Committee of National Cheng Kung University Hospital (HEEC No: --/B-ER-101-041). Participation in the interview process implied consent to participate in this study. Participants could opt out at any stage of the study.

The Taiwan Longitudinal Study on Aging (TLSA) has conducted seven waves of surveys on a nationally representative sample of late-middle-aged and older adults since 1989. The TLSA used a three-stage probability sampling method based on the national household register. Remote mountainous aboriginal townships were excluded. Trained interviewers home-visited the cohort and conducted a structured interview in each wave. The response rate has been $\sim 90 \%$ in six of the seven surveys. ${ }^{10}$ The present study used the data from the last four surveys (1996, 1999, 2003, and 2007). We included 5,058 participants $>50$ years old in this study. A proxy would be interviewed whenever a participant was unable to be interviewed due to any physical or mental conditions. Subjective questions, for example, on depression or cognitive tasks, could not be answered by proxy and were thus coded with specific missing codes. Initially, we only analyzed those participants without missing values. We tried different ways of imputation in the sensitivity analysis to test the robustness of our final inferences, for which all subjects were included.

\section{Measurements}

\section{Gardening and mortality}

The participants were first asked if they grew flowers, gardened, or cultivated potted plants for pleasure. If they said yes, then they were asked how often they did this: 1) less than once a month, 2) two to three times a month, 3) once or 
twice a week, or 4) almost daily. The four frequencies were dummied with nongardener as the reference. The end-point was either the year the participant died, based on the national mortality registry until December 31, 2007, or the censored year of the last interview or of the emigration registry.

\section{Comorbidities, mobility, and depression}

Mortality and mobility limitations among the older adults are highly associated with major illnesses, and the present study thus includes six comorbidities that are common among old people: diabetes, hypertension and heart disease, stroke, cancer, lung disease, and kidney disease. "Mobility limited" was defined as "requiring aids or another person, or having difficulty doing any of the following eight tasks alone." To compare the differences between gardeners and nongardeners at baseline, mobility limitations were classified as follows: A "mild mobility limitation" was defined as having difficulty squatting, lifting an $11 \mathrm{~kg}$ weight, or running 20-30 m; a "moderate mobility limitation" as having difficulty standing for 15 minutes, walking 200-300 m, or climbing up two to three floors; and a "severe mobility limitation" as having difficulty raising one's arms up or grasping with one's fingers. ${ }^{11}$ Self-reported depressive symptoms were assessed using the ten-item version of the Center for Epidemiologic Studies Depression Scale, and a summed score (range: $0-30$ ) >10 was coded as "depressed mood." $" 12,13$

\section{Demographics and SES}

The demographic factors include age, sex, with or without a domestic partner, and employment. Because socioeconomic status (SES) might confound the relationship between gardening and mortality, four items were identified as SES proxies: education, residence, employment, and satisfaction with current economic status. Many old people in Taiwan did not receive a formal education, and participants with a higher level of education might have a better chance of achieving a better SES. Years of education are categorized as $<7$ (primary school), 7-12 (secondary school: junior and senior high school), and $>12$ (tertiary school: junior college and above). Employment is dichotomous (yes/no). Residence is categorized as city (urban), town (suburban), and countryside. Direct inquiries about the participants' income and personal property yielded many missing values. Therefore, satisfaction with current economic status, which did not have so many missing values, is used as the fourth SES proxy. According to the self-reported levels of satisfaction on a 5-point Likert scale, the participants were classified as unsatisfied, average, and satisfied.

\section{Health behaviors and conditions}

Three important health behaviors that might be related to mortality and gardening were included: smoking, drinking, and exercise. The first two were binary: current smokers and alcohol drinkers, regardless of frequency and amount, were coded positive. The third was categorized by weekly frequency: $\leq 5$ times/week $=$ infrequent exercisers, and $\geq 6$ times/week $=$ regular exercisers. Any difficulty in six instrumental activities of daily living (IADLs), ${ }^{14,15}$ including shopping for groceries, ability to handle finances, mode of transportation, heavy housekeeping, such as cleaning windows or the ditches surrounding the house, light housekeeping, such as sweeping floor or washing dishes, and ability to use a telephone, was coded as "IADL impaired."

\section{Statistical analysis}

SAS 9.4 (SAS Institute Inc., Cary, NC, USA) was used for all statistical analyses. The potential confounders - demographics, SES, health behaviors, comorbidities, mobility, and depression - were stepwise included in the models. We also examined the mortality hazards of gardening in the full models stratified by mobility limitations and depression at baseline. Time-dependent values of three groups of variables - six comorbidities, mobility limitations, and depression - were the last available values in the four surveys used as our dataset.

Sensitivity analyses were conducted to examine the effects of missing values. There were 4,501 participants with no missing values for baseline variables of interest, but there were 414 participants without valid Center for Epidemiologic Studies Depression Scale-10 and 385 who did not report whether they were satisfied with their current economic status. The participants with missing values appeared to be significantly older, less active, and more depressed, and to have less education, more comorbidities, and more mobility limitations at baseline. Because any missing value from a participant would impede the contribution of the other available information, we used three different imputation methods. The first was "last value carried forward" to impute the missing values of the time-dependent covariates: any missing value before a participant was censored or deceased was imputed using the last available value from the previous surveys. The second was to impute the in-between missing values by averaging two near ends, and using last value carried forward if the missing values were from the last available survey. The third was assigning median values to those that were missing.

\section{Results}

We analyzed 5,058 participants: 1,029 (20.3\%) daily gardeners, $3,547(70.1 \%)$ nongardeners, and the rest with in-between 
gardening frequencies (male: 53.4\%; mean age: 66.6 \pm 9.4 years; with at least one of the six comorbidities: 1,557 [30.9\%]). Daily gardeners had lower mortality and were more educated and urbanized, less satisfied with their income, and healthier than their nongardener counterparts at baseline (Tables 1 and S1 for gardeners with in-between frequencies). Of 1,783 participants who reported themselves as daily gardeners, 895 (50.2\%) remained as daily gardeners in another survey.

Daily home gardening at baseline was associated with better survival when only age, sex, and with or without a domestic partner had been adjusted for (hazard ratio [HR]: $0.67 ; 95 \%$ confidence interval [CI]: $0.59-0.76)$ or when all baseline covariates had been adjusted for (HR: 0.82; CI: 0.71-0.94 in Model F) (Table 2). No dose effect of different gardening frequencies was found (Tables S2 and S3). The HR seemed to stabilize once demographics, SES, IADL, and health behaviors had been adjusted for in the models (Table 2), despite the potential direct effects of comorbidities, mobility limitations, and depression on mortality.
The protective effect of daily gardening at baseline decreased for those with later comorbidities, mobility limitations, and depression (HR: 0.87; CI: 0.73-1.02 in Model T-4) (Table 3). To clarify the effects of mobility and depression, we also stratified the participants by mobility limitations and selfreported depression at baseline. The positive effect of daily gardening was robust among those with any mobility limitation and without depression at baseline, but not among those without a mobility limitation or with depression (Table 2). For those who had chronic mobility limitations but no depression at baseline, baseline daily gardening appeared to be significantly beneficial for survival (HR: 0.64; CI: 0.48-0.87 in Model T-5) (Table 3) after time-dependent comorbidities, mobility, depression (Table 3 ), and cognitive function (Table S4) had been adjusted for. However, the conferred protection level fell for participants with mobility limitations who had relapsed or chronic depression (Model T-5) (Table 3). For those who reported any IADL impairment at baseline $(\mathrm{N}=1,415)$, our exploratory analyses yielded a protective

Table I Baseline demographic and physical characteristics of participants in 1996 stratified by nongardeners and daily gardeners

\begin{tabular}{|c|c|c|c|}
\hline Variables & Total & Nongardener & Almost daily \\
\hline No deceased/no total & $1,893 / 5,058$ & $\mathrm{I}, 443 / 3,547$ & $310 / 1,029$ \\
\hline Follow-up time (years) & $8.8(3.4)$ & $8.5(3.6)$ & $9.4(2.8)$ \\
\hline Age (50-97) (years) & $66.6(9.37)$ & $67.2(9.6)$ & $65.8(8.9)$ \\
\hline Education (years) & $4.7(4.5)$ & $4.1(4.3)$ & $5.8(4.7)$ \\
\hline Male (\%) & $2,691(53.4)$ & $1,903(53.7)$ & $528(51.3)$ \\
\hline Married (\%) & $3,577(70.9)$ & $2,438(68.7)$ & $788(76.6)$ \\
\hline Employed (\%) & $\mathrm{I}, 5 \mathrm{I} 4(30.1)$ & $\mathrm{I}, 045(29.5)$ & $317(30.8)$ \\
\hline Resided in city (\%) & I,884 (37.6) & $1,246(35.5)$ & $449(43.9)$ \\
\hline In town (\%) & I,I59 (23.I) & $800(22.8)$ & $243(23.8)$ \\
\hline In countryside (\%) & $1,969(39.3)$ & $\mathrm{I}, 468(41.2)$ & $331(32.4)$ \\
\hline Nonsmokers (\%) & $3,779(75)$ & $2,653(74.8)$ & $776(75.5)$ \\
\hline Nondrinkers (\%) & $4,052(80.4)$ & $2,889(81.5)$ & $797(77.5)$ \\
\hline \multicolumn{4}{|l|}{ Frequency of exercise } \\
\hline None (\%) & 2,477 (49.1) & I,979 (55.8) & $304(29.5)$ \\
\hline I-5 times/week (\%) & $666(13.2)$ & $430(12.1)$ & $142(13.8)$ \\
\hline$\geq 6$ times/week (\%) & $\mathrm{I}, 898(37.7)$ & $1,136(32.1)$ & $583(56.7)$ \\
\hline IADL impaired ${ }^{a}(>0)(\%)$ & I,705 (34.0) & $1,358(38.6)$ & $233(22.7)$ \\
\hline Diabetes mellitus (\%) & $489(9.7)$ & $36 I(10.2)$ & $87(8.5)$ \\
\hline Heart disease (\%) & $598(11.9)$ & $444(12.5)$ & $113(11.0)$ \\
\hline Stroke (\%) & $192(3.8)$ & $166(4.7)$ & $20(1.9)$ \\
\hline Cancer (\%) & $67(1.3)$ & $45(\mathrm{I} .3)$ & $18(1.8)$ \\
\hline Lung disease (\%) & $412(8.2)$ & $322(9.1)$ & $60(1.8)$ \\
\hline Kidney disease (\%) & $343(6.8)$ & $253(7.2)$ & $60(5.9)$ \\
\hline \multicolumn{4}{|l|}{ Mobility limitation ${ }^{\mathrm{b}}$} \\
\hline None (\%) & $2,867(56.9)$ & $\mathrm{I}, 889(53.7)$ & $690(67.1)$ \\
\hline Mild (\%) & $817(16.2)$ & $544(15.4)$ & $187(18.2)$ \\
\hline Moderate (\%) & $906(18.0)$ & $724(20.5)$ & $119(11.6)$ \\
\hline Severe $(\%)$ & $440(8.8)$ & $380(10.7)$ & $32(3.1)$ \\
\hline Depressed mood $(>10)(\%)^{c}$ & $\mathrm{I}, 024(22.1)$ & $798(25.0)$ & $156(15.8)$ \\
\hline
\end{tabular}

Notes: All data are presented as frequencies (percentage), except for follow-up time, age, and education which are presented as mean (standard deviation). aIADL: any difficulty in shopping for groceries, ability to handle finances, mode of transportation, heavy housekeeping, light housekeeping, and ability to use a telephone. limitation: any difficulty in squatting, lifting an II kg weight, or running 20-30 m; moderate mobility limitation: any difficulty standing for 15 minutes, walking 200-300 m, or climbing up two to three floors; severe mobility limitation: raising one's arms up or grasping with one's fingers." 'Measured using the Center for Epidemiologic Studies Depression (CESD-10) Scale (range: 0-30; cutoff: 10). ${ }^{12}$

Abbreviations: CESD-10, Center for Epidemiologic Studies Depression I0; IADL, instrumental activities of daily living. 
Table $2 \mathrm{HR}$ and $95 \% \mathrm{Cl}$ of baseline daily gardening on all-cause mortality and each model mutually adjusted for covariates at baseline

\begin{tabular}{|c|c|c|c|c|}
\hline \multirow{2}{*}{\multicolumn{2}{|c|}{ Model construction }} & \multicolumn{2}{|c|}{ Number } & \multirow{2}{*}{$\begin{array}{l}\text { HR }(\mathrm{Cl}) \text { of daily gardening } \\
\text { (reference: nongardener) }\end{array}$} \\
\hline & & At risk & Deceased & \\
\hline \multicolumn{2}{|c|}{ Unadjusted model } & 5,043 & 1,893 & $0.65(0.57-0.74)$ \\
\hline \multicolumn{2}{|c|}{ Model A: Adjusted for age, sex, with or without a domestic partner } & 5,043 & 1,893 & $0.67(0.59-0.76)$ \\
\hline \multicolumn{2}{|c|}{ Model B: Model A + education, employment, residence, income satisfaction } & 4,615 & 1,631 & $0.73(0.64-0.83)$ \\
\hline \multicolumn{2}{|c|}{ Model C: Model B + smoking, drinking, exercising, IADL } & 4,580 & 1,611 & $0.80(0.70-0.92)$ \\
\hline \multicolumn{2}{|c|}{ Model D: Model C + diabetes, stroke, cancer, lung, heart, kidney disease } & 4,559 & 1,604 & $0.80(0.70-0.92)$ \\
\hline \multicolumn{2}{|c|}{ Model E: Model D + mobility limitations } & 4,551 & 1,600 & $0.83(0.72-0.95)$ \\
\hline \multicolumn{2}{|c|}{ Model F: Model E + depression } & 4,501 & $\mathrm{I}, 578$ & $0.82(0.7 \mathrm{I}-0.94)$ \\
\hline \multicolumn{5}{|c|}{ Model G: Model D stratified by mobility limitations and depression at baseline: } \\
\hline \multicolumn{5}{|c|}{ Mobility limitations versus depression: } \\
\hline$(-)$ & $(-)$ & 2,359 & 564 & $1.00(0.8 I-1.23)$ \\
\hline$(+)$ & $(-)$ & $\mathrm{I},|4|$ & 536 & $0.64(0.50-0.82)$ \\
\hline$(-)$ & $(+)^{\mathrm{a}}$ & 324 & 94 & $0.80(0.43-1.13)$ \\
\hline$(+)$ & $(+)^{\mathrm{a}}$ & 653 & 377 & $0.67(0.46-0.97)$ \\
\hline
\end{tabular}

Note: aGroups with small sample size and invalid HR were deleted. Models A-G were stepwise adjusted for potential confounders. "(+)” indicates yes; “( -$)$ ” indicates no. Abbreviations: $\mathrm{Cl}$, confidence interval; $\mathrm{HR}$, hazard ratio; IADL, instrumental activities of daily living.

effect of daily gardening (HR: 0.58; CI: 0.43-0.79) adjusted for covariates and three sets of time-dependent variables, regardless of cognitive condition (Table S5).

For those who had neither depression nor a mobility limitation at baseline, there was no long-term benefit of gardening at baseline. The sensitivity analyses showed a consistent protective effect of gardening, regardless of the method used to impute missing values (Table 4), namely, the results of reduced mortality among daily gardeners might be underestimated because of the exclusion of missing values.

\section{Discussion}

We found that, for people $>50$ years old with mobility limitations, daily home gardening as a leisure-time activity seems to postpone $\sim 36 \%$ of mortality. It is noteworthy that this protection did not apply to people without mobility limitations at baseline (Model G in Table 2 and Model T-5 in Table 3). The positive effects of light-intensity and solitary gardening on survival appear to have some therapeutic component in addition to their preventative effect. We cannot completely rule out that daily gardeners with mobility limitations have less severe health conditions at baseline than do nongardeners. Infrequent gardening would not generate any statistically significant protection. Therefore, we reported only the results in fully adjusted models so that we would not overestimate the effects of gardening. Additionally, our finding that daily gardening reduced the risk of mortality by $\sim 18 \%$ in the older general population (Model F in Table 2) is similar to that reported in two Danish studies. ${ }^{3,16}$ For those individuals with mobility limitations, possibly caused by aging or morbidities, daily gardening for pleasure may increase longevity.

Table $3 \mathrm{HR}$ and $95 \% \mathrm{Cl}$ of baseline daily gardening on all-cause mortality adjusted for time-dependent covariates ${ }^{\mathrm{a}}$

\begin{tabular}{|c|c|c|c|c|}
\hline \multirow{2}{*}{\multicolumn{2}{|c|}{ Time-dependent variables }} & \multicolumn{2}{|c|}{ Number } & \multirow{2}{*}{$\begin{array}{l}\text { HR }(\mathrm{CI}) \text { of daily gardening } \\
\text { (reference: nongardener) }\end{array}$} \\
\hline & & At risk & Deceased & \\
\hline \multicolumn{2}{|c|}{ Model T-I: comorbidities } & 4,521 & 1,291 & $0.81(0.69-0.94)$ \\
\hline \multicolumn{2}{|c|}{ Model T-2: comorbidities + mobility limitations } & 4,530 & 1,291 & $0.82(0.70-0.96)$ \\
\hline \multicolumn{2}{|c|}{ Model T-3: comorbidities + depression } & 4,571 & 1,084 & $0.85(0.72-1.00)$ \\
\hline \multicolumn{2}{|c|}{ Model T-4: comorbidities + mobility limitations + depression } & 4,580 & 1,085 & $0.87(0.73-1.02)$ \\
\hline \multicolumn{5}{|c|}{ Model T-5: model T-4 stratified by mobility limitations and depression at baseline: } \\
\hline \multicolumn{5}{|c|}{ Mobility limitations versus depression ${ }^{\mathrm{b}}$ : } \\
\hline$(-)$ & $(-)$ & 2,408 & 386 & I.I I (0.87-I.72) \\
\hline$(+)$ & $(-)$ & $\mathrm{I}, \mathrm{I} 45$ & 367 & $0.64(0.48-0.87)$ \\
\hline$(-)$ & $(+)^{c}$ & 332 & 63 & $0.93(0.46-1.87)$ \\
\hline$(+)$ & $(+)^{c}$ & 658 & 243 & $0.64(0.39-1.04)$ \\
\hline
\end{tabular}

Notes: all models adjusted for socioeconomic status (age, sex, with or without a domestic partner, education, employment, residence, income satisfaction), health behaviors (smoking, drinking, exercising), and IADL at baseline; and time-dependent comorbidities, mobility limitations, and depression at baseline if not modeled as timedependent variables. 'According to Model T-4, stratified by baseline mobility limitations and depression. 'Groups with a small sample size and invalid HR were deleted. "( + )" indicates yes; "(-)" indicates no.

Abbreviations: $\mathrm{Cl}$, confidence interval; HR, hazard ratio; IADL, instrumental activities of daily living. 
Table 4 Sensitivity tests for missing values: last value carried forward and pseudomedian values

\begin{tabular}{lllll}
\hline Frequency of gardening & $<$ I time/month & 2-3/month & I-2/week & Almost daily \\
\hline Model SI & $0.57(0.32-1.00)$ & $1.05(0.7 I-1.57)$ & $0.86(0.67-1.07)$ & $0.86(0.75-0.98)$ \\
Model S2 & $0.57(0.32-1.01)$ & $1.07(0.72-1.60)$ & $0.86(0.69-1.07)$ & $0.84(0.73-0.96)$ \\
Model S3 & $0.52(0.29-0.92)$ & $0.91(0.57-1.43)$ & $0.90(0.72-1.13)$ & $0.81(0.70-0.94)$ \\
\hline
\end{tabular}

Notes: Model SI: LVCF for imputation. Model S2: in-between missing imputed using the mean of the two near ends; if missing at the last available interview, imputed using LVCF. Model S3: missing imputed using pseudomedian of variables. All models show hazard ratio and $95 \%$ confidence interval of baseline daily gardening on all-cause mortality adjusted for socioeconomic status (age, sex, with or without a domestic partner, education, employment, residence, income satisfaction), health behaviors (smoking, drinking, exercising), and IADL at baseline; and time-dependent comorbidities, mobility limitations, and depression.

Abbreviations: IADL, instrumental activities of daily living; LVCF, last value carried forward.

Gardening in many Western countries might involve something akin to yardwork, because the garden is usually large and the activity involves a great deal of walking and other yard-related exercise (eg, mowing or raking the lawn), especially of the legs and arms. Gardening in Taiwan, however, more frequently means growing plants in flowerpots or other improvised containers (eg, plastic beverage bottles) on the sunporch or in front of the door in urban and suburban areas (Figure 1). Because Taiwan is densely populated (648 persons $/ \mathrm{km}^{2}$ ) and because two-thirds of the land on its main island is occupied by high mountains, relatively few households can afford an outdoor garden. Our flowerpot gardening activities, such as pruning and watering, require mostly low-intensity upper-body movement (metabolic equivalents $<3$ in Korean older adults) ${ }^{17}$ in contrast, having an outdoor vegetable or flower garden as a leisure activity, which requires moderate-intensity upper- and lower-body movement, ${ }^{18}$ is less common in Taiwan. In our study, a mobility limitation means requiring aids (eg, a walker, a cane, or a wheelchair) or another person, or having difficulty doing any of the following eight tasks alone: squatting, lifting an $11 \mathrm{~kg}$ weight, running $20-30 \mathrm{~m}$, standing for 15 minutes, walking 200-300 m, climbing up two to three floors, raising one's arms up, and grasping with one's fingers. Five of these tasks involve mostly the lower body. Elderly gardeners who have difficulty running 20-30 m may add to their life expectancy by engaging in the upper body movements required to transplant and water potted plants. Gardening for more than an hour per week was associated with fast gait speed and good performance in the semitandem and full-tandem balance tests among 3,237 American old adults. ${ }^{19}$ Compared with other more strenuous physical activities, for example, walking and cycling, home gardening is possible for people with mobility limitations. In contrast, elderly gardeners without any mobility limitations would be less likely to gain additional years of survival from the low-energy exercise provided by home gardening.
Daily gardening "for pleasure" implies that motivation might explain some of the protective effects of gardening. A survey of 126 visitors to a garden center on their attitudes toward gardening found that appreciation for nature and concerns for other people were the main benefits of gardening. ${ }^{20}$ Another mail survey of 303 volunteers from a university aging and cognition lab used a motivation questionnaire for leisure in general, and reported seven motivational factors for gardening: 1) intellectual, 2) stimulus-avoidance, 3) friendship building, 4) social interaction, 5) physical fitness, 6) skilldevelopment, and 7) creativity. ${ }^{21}$ Because home gardening involves neither large-scale outdoor gardens nor another person, we were unable to differentiate whether there were motivations involving the outdoor natural environment, ${ }^{22}$ friendship, or economic factors, ${ }^{23}$ and it may be that these are not applicable in urban or suburban Taiwan. Nonetheless, motivations relevant to plants, intrapersonal emotions, cognition, and physical skills and abilities might contribute to gardening for pleasure. Additionally, leisure participation and physical activities in older adults are often a continuation of what these individuals used to do in the first half of their lives. ${ }^{24-26}$ However, health conditions ${ }^{26}$ and a lack of interest in the activities seemed to be common obstacles to continuity of such actions, ${ }^{25}$ and previous participation was a consistent predictor. ${ }^{24}$ While only $50 \%$ continued their home gardening in this 11-year follow-up, in comparison to an 8-year follow-up of 380 Canadian older adults, $67.5 \%$ of whom continued their outdoor yardwork, ${ }^{26}$ engagement in pleasurable voluntary activity seemed to confer survival advantages.

Nature affects health through four proposed pathways: air quality, social cohesion, physical activity, and stress reduction, ${ }^{22}$ and daily home gardening seems most likely to be on the physical activity (despite its low intensity) and stress reduction pathways. There is an abundance of reports $8,22,27-29$ on the psychological benefits of gardening. However, we found that gardening had no effect at all for people with 
depression but without a mobility limitation, although it was helpful to people with a mobility limitation and with no comorbid depression. The reciprocal relation between depression and brain dysfunction might facilitate a pervasive negative impact, ${ }^{30}$ including disability and mortality. ${ }^{31}$ Depression deteriorates health, mentally and physically, and chronic or relapsed self-reported depression seemed to weaken the benefits of home gardening for survival. Home gardening in Taiwan probably has little or no protective effect against allcause mortality in the older adults with depression, possibly because the intensity of such activity is low and it may offer relatively limited psychological benefits. Depression in the older adults requires separate effective treatment.

This study has some limitations. First, no details of gardening other than frequency were available in the TLSA dataset. We thus were unable to create other relevant models or to make any recommendations for the duration, intensity, body movement, and psychological elements of gardening, other than frequency. However, frequent nonexercise physical activities (performing home repairs; cutting a lawn, hedge, and so on; car maintenance; taking bicycle rides, skiing, iceskating, going hunting or fishing; and gathering mushrooms or berries) were shown to reduce mortality in Sweden. ${ }^{32}$ While this study may have clarified how home gardening works among an older Taiwanese population, we were unable to generalize to other leisure activities with similar potential mechanism. Second, because of the limited sample size, we were unable to stratify the results by morbidities or various degrees of mobility limitations to examine the effects of gardening in more detail. Third, despite the preliminary protective effect of daily gardening among those with IADL impairments at baseline, the disablement process of dementia might be different, and further research with a larger sample size would validate and shed light on our exploratory findings. Although the above mechanisms are still open to additional studies, home gardening might be an easy-to-start and sustainable leisure activity worth recommending to older adults, particularly those who have mobility limitations. The entry-level investment for home gardening is low: a container and a plant. Moreover, there is an abundance of aids and tools for older adults who are wheelchair-bound or who have other mobility limitations, and thus gardening as a leisure activity can easily be prolonged despite limitations that might interrupt other physical and social activities. However, additional research is needed to explore whether the social interactions and outdoor psychological advantages of gardening in an allotment (ie, working in a community garden primarily for growing vegetables: http://www.allotment-garden.org/) or large private garden confer significantly more protection than tending to small, inside-the-house flowerpot "gardens" against chronic depression on mortality.

\section{Conclusion}

In this 11-year follow-up nationwide study, daily gardening was consistently shown to reduce mortality after the confounding factors of age, sex, SES, health behaviors and condition, and time-dependent illness conditions, and even using different methods to impute missing values, were adjusted for. Daily home gardening was particularly protective of survival for people with baseline mobility limitations but without depression. It may thus be worthwhile to recommend gardening to middle-aged and older adults as a daily activity, although additional investigations of the physical and psychological effects of gardening are needed.

\section{Acknowledgments}

We thank Professor Jing-Hsiang Hwang of Academia Sinica for advising us on imputation methods for the missing values, and Bill Franke and Paul Steed for English editing and proofreading. This study is based on the data from the TLSA, provided by the Bureau of Health Promotion, Department of Health, Taiwan. The descriptions or conclusions herein do not represent the viewpoint of the Bureau. The fee of English editing of the revised manuscript was supported by the project funded by the Ministry of Science and Technology (MOST 104-2314-B-006-023).

\section{Disclosure}

This work received no outside funding. The authors report no conflicts of interest in this work.

\section{References}

1. World Health Organization. Global Recommendations on Physical Activity for Health; 2010. Available from: http://whqlibdoc.who.int/ publications/2010/9789241599979_eng.pdf. Accessed November 2, 2015.

2. Nelson ME, Rejeski WJ, Blair SN, et al. Physical activity and public health in older adults: recommendation from the American College of Sports Medicine and the American Heart Association. Med Sci Sports Exerc. 2007;39(8):1435-1445.

3. Johnsen NF, Ekblond A, Thomsen BL, Overvad K, Tjonneland A. Leisure time physical activity and mortality. Epidemiology. 2013;24(5): 717-725.

4. Glass TA, de Leon CM, Marottoli RA, Berkman LF. Population based study of social and productive activities as predictors of survival among elderly Americans. BMJ. 1999;319(7208):478-483.

5. Haapanen N, Miilunpalo S, Vuori I, Oja P, Pasanen M. Characteristics of leisure time physical activity associated with decreased risk of premature all-cause and cardiovascular disease mortality in middle-aged men. $\mathrm{Am}$ J Epidemiol. 1996;143(9):870-880. 
6. Sabia S, Dugravot A, Kivimaki M, Brunner E, Shipley MJ, SinghManoux A. Effect of intensity and type of physical activity on mortality: results from the Whitehall II cohort study. Am J Public Health. 2012; 102(4):698-704.

7. Kaplan R. Some psychological benefits of gardening. Environ Behav. 1973;5(2):145-162.

8. Bringslimark T, Hartig T, Patil GG. The psychological benefits of indoor plants: a critical review of the experimental literature. J Environ Psychol. 2009;29:422-433.

9. Wang DC, MacMillan T. The benefits of gardening for older adults: a systematic review of the literature. Act Adapt Aging. 2013;37:153-181.

10. 2007 Taiwan Longitudinal Study on Aging (TLSA)-the 6th wave of survey. Health Promotion Administration, Ministry of Health and Welfare. Available from: https://olap.hpa.gov.tw/en_US/search/ ListHealth 1 . asp $x$ menu $=1 \&$ mode $=5 \&$ year $=96 \&$ sel $=0 \& \operatorname{mid}=3$. Accessed March 21, 2014.

11. Yeh CJ, Wang CY, Tang PF, Lee MC, Lin HS, Chen HY. Hierarchy of higher-level physical functions: a longitudinal investigation on a nationally representative population of community-dwelling middleaged and elderly persons. Disabil Rehabil. 2012;34(15):1271-1276.

12. Andresen EM, Malmgren JA, Carter WB, Patrick DL. Screening for depression in well older adults: evaluation of a short form of the CES-D (Center for Epidemiologic Studies Depression Scale). Am J Prev Med. 1994;10(2):77-84.

13. Chang KF, Weng LJ. Screening for depressive symptoms among older adults in Taiwan: Cutoff of a short form of the Center for Epidemiologic Studies Depression Scale. Health. 2013;5(3A):588-594.

14. Baltes MM, Maas I, Wilms H-U, Borchelt M, Little TD. Everyday competence in old and very old age: Theoretical considerations and empirical findings. In: Baltes PB, Mayer KU, editors. The Berlin Aging Study: Aging from 70 to 100. New York: Cambridge University Press; 1999:384-402.

15. Lawton MP. Scales to measure competence in everyday activities. Psychopharmacol Bull. 1988;24(4):609-614.

16. Andersen ZJ, de Nazelle A, Mendez MA, et al. A study of the combined effects of physical activity and air pollution on mortality in elderly urban residents: the Danish Diet, Cancer, and Health cohort. Environ Health Perspect. 2015;123(6):557-563.

17. Park SA, Lee KS, Son KC. Determining exercise intensities of gardening tasks as a physical activity using metabolic equivalents in older adults. HortScience. 2011;46(12):1706-1710.
18. Park SA, Lee KS, Son KC, Shoemaker CA. Metabolic cost of horticulture activities in older adults. J Japan Soc Hort Sci. 2012;81(3):295-299.

19. Chen TY, Janke MC. Gardening as a potential activity to reduce falls in older adults. J Aging Phys Act. 2012;20(1):15-31.

20. Clayton S. Domesticated nature: motivations for gardening and perceptions of environmental impact. J Environ Psychol. 2007;27:215-224.

21. Ashton-Shaeffer C, Constant A. Why do older adults garden? Act Adapt Aging. 2006;30(2):1-18.

22. Hartig T, Mitchell R, de Vries S, Frumkin H. Nature and health. Annu Rev Public Health. 2014;35:207-228.

23. Church A, Mitchell R, Ravenscroft N, Stapleton LM. 'Growing your own': a multi-level modelling approach to understanding personal food growing trends and motivations in Europe. Ecol Econ. 2015;110: 71-80.

24. Agahi N, Ahacic K, Parker MG. Continuity of leisure participation from middle age to old age. J Gerontol B Psychol Sci Soc Sci. 2006; 61(6):S340-S346.

25. Paivi M, Mirja H, Terttu P. Changes in physical activity involvement and attitude to physical activity in a 16-year follow-up study among the elderly. J Aging Res. 2010;2010:174290.

26. Strain LA, Grabusic CC, Searle MS, Dunn NJ. Continuing and ceasing leisure activities in later life: a longitudinal study. Gerontologist. 2002; 42(2):217-223.

27. Clatworthy J, Hinds J, Camic PM. Gardening as a mental health intervention: a review. Ment Health Rev (Brighton). 2013;18(4):214-225.

28. Adams KB, Leibbrandt S, Moon H. A critical review of the literature on social and leisure activity and wellbeing in later life. Ageing Soc. 2011; 31(4):683-712.

29. Gonzalez MT, Hartig T, Patil GG, Martinsen EW, Kirkevold M. Therapeutic horticulture in clinical depression: a prospective study of active components. J Adv Nurs. 2010;66(9):2002-2013.

30. Alexopoulos GS. Depression in the elderly. Lancet. 2005;365(9475): 1961-1970.

31. Rodda J, Walker Z, Carter J. Depression in older adults. BMJ. 2011; 343:d5219.

32. Ekblom-Bak E, Ekblom B, Vikstrom M, de Faire U, Hellenius ML. The importance of non-exercise physical activity for cardiovascular health and longevity. Br J Sports Med. 2014;48(3):233-238. 


\section{Supplementary materials}

Table SI Baseline demographic and physical characteristics of participants in 1996 stratified by 5-frequency gardening

\begin{tabular}{|c|c|c|c|c|c|c|}
\hline \multirow[t]{2}{*}{ Variables } & \multirow{2}{*}{$\frac{\text { Total } N}{1,893 / 5,058^{*}}$} & \multirow{2}{*}{$\frac{\text { Nongardener }}{1,443 / 3,547^{*}}$} & \multirow{2}{*}{$\frac{<I \text { time/month }}{|5 / 6|^{*}}$} & \multirow{2}{*}{$\frac{2-3 / \text { month }}{27 / 94^{*}}$} & \multirow{2}{*}{$\frac{1-2 / \text { week }}{98 / 312^{*}}$} & \multirow{2}{*}{$\frac{\text { Almost daily }}{310 / 1,029 *}$} \\
\hline & & & & & & \\
\hline Follow-up time (years) & $8.8(3.4)$ & $8.5(3.6)$ & $9.8(2.3)$ & $9.2(3.2)$ & $9.3(3.0)$ & $9.4(2.8)$ \\
\hline Age (50-97) (years) & $66.6(9.37)$ & $67.2(9.6)$ & $65.4(9.1)$ & $64.2(8.7)$ & $65.4(8.6)$ & $65.8(8.9)$ \\
\hline Education (years) & $4.7(4.5)$ & $4.1(4.3)$ & $5.9(5.2)$ & $6.1(4.9)$ & $5.8(4.5)$ & $5.8(4.7)$ \\
\hline Male (\%) & $2,691(53.4)$ & I,903 (53.7) & $38(62)$ & $53(56)$ & $169(54.2)$ & $528(5 \mid .3)$ \\
\hline Married (\%) & $3,577(70.9)$ & 2,438 (68.7) & $47(77)$ & 74 (79) & $230(73.7)$ & $788(76.6)$ \\
\hline Employed (\%) & $1,514(30.1)$ & I,045 (29.5) & $24(39)$ & $30(32)$ & $98(31.5)$ & $317(30.8)$ \\
\hline Resided in city (\%) & I,884 (37.6) & I,246 (35.5) & $31(50)$ & $36(39)$ & II3 (36.8) & 449 (43.9) \\
\hline In town (\%) & I, I59 (23.I) & $800(22.8)$ & $15(25)$ & $24(26)$ & $73(23.8)$ & $243(23.8)$ \\
\hline In countryside (\%) & I,969 (39.3) & I,468 (4I.2) & $15(25)$ & $32(35)$ & I2I (39.4) & 331 (32.4) \\
\hline \multicolumn{7}{|c|}{ Satisfaction with current economic status } \\
\hline Feeling average with income (\%) & $2,07 \mid(44.4)$ & I,466 (45.6) & $18(32.4)$ & $39(43.3)$ & $126(4 \mid .9)$ & $422(42.2)$ \\
\hline Unsatisfied with income (\%) & $\mathrm{I}, 778(38 . \mathrm{I})$ & $\mathrm{I}, \mathrm{I} 27(35 . \mathrm{I})$ & $31(55.4)$ & $38(42.2)$ & I $34(44.5)$ & $448(44.8)$ \\
\hline Satisfied with income (\%) & $813(17.4)$ & $622(19.3)$ & $7(12.5)$ & $13(14.4)$ & $4 \mid(13.6)$ & $130(13.0)$ \\
\hline Nonsmokers (\%) & $3,779(75)$ & $2,653(74.8)$ & $45(75)$ & $68(72)$ & $237(76.0)$ & $776(75.5)$ \\
\hline Nondrinkers (\%) & $4,052(80.4)$ & $2,889(81.5)$ & $4 \mathrm{I}(67)$ & $75(80)$ & $250(80.1)$ & $797(77.5)$ \\
\hline \multicolumn{7}{|l|}{ Frequency of exercise } \\
\hline None (\%) & $2,477(49.1)$ & $\mathrm{I}, 979(55.8)$ & $23(38)$ & $39(42)$ & $132(42.3)$ & $304(29.5)$ \\
\hline I-5 times/week (\%) & $666(13.2)$ & $430(12.1)$ & $20(33)$ & $15(16)$ & $59(18.4)$ & $142(13.8)$ \\
\hline$\geq 6$ times/week $(\%)$ & $\mathrm{I}, 898(37.7)$ & $\mathrm{I}, \mathrm{I} 36(32.1)$ & $18(30)$ & $40(43)$ & $|2|(38.8)$ & $583(56.7)$ \\
\hline IADL impaired ${ }^{a}(>0)(\%)$ & $\mathrm{I}, 705(34.0)$ & I,358 (38.6) & $15(25)$ & $18(19)$ & $81(26.1)$ & $233(22.7)$ \\
\hline Diabetes mellitus (\%) & $489(9.7)$ & $36 \mathrm{I}(10.2)$ & $6(10)$ & II (II) & $24(7.7)$ & $87(8.5)$ \\
\hline Heart disease (\%) & $598(11.9)$ & $444(12.5)$ & $3(5)$ & $9(10)$ & $29(9.3)$ & $113(11.0)$ \\
\hline Stroke (\%) & $192(3.8)$ & $166(4.7)$ & $2(3)$ & 0 & $4(1.3)$ & $20(1.9)$ \\
\hline Cancer (\%) & $67(1.3)$ & $45(1.3)$ & I (2) & $I(I)$ & $2(0.6)$ & $18(1.8)$ \\
\hline Lung disease (\%) & $412(8.2)$ & $322(9.1)$ & $2(3)$ & $7(8)$ & $21(6.8)$ & $60(1.8)$ \\
\hline Kidney disease (\%) & $343(6.8)$ & $253(7.2)$ & $2(3)$ & $8(9)$ & $20(6.5)$ & $60(5.9)$ \\
\hline \multicolumn{7}{|l|}{ Mobility limitation ${ }^{\mathrm{b}}$} \\
\hline None (\%) & $2,867(56.9)$ & $\mathrm{I}, 889(53.7)$ & $41(68)$ & $55(59)$ & $192(61.7)$ & $690(67.1)$ \\
\hline Mild (\%) & $817(16.2)$ & $544(I 5.4)$ & $6(10)$ & $14(15)$ & $66(21.2)$ & $187(18.2)$ \\
\hline Moderate (\%) & $906(18.0)$ & 724 (20.5) & $8(13)$ & $19(20)$ & $36(11.6)$ & $119(11.6)$ \\
\hline Severe (\%) & $440(8.8)$ & $380(10.7)$ & $5(8)$ & $6(6)$ & $17(5.5)$ & $32(3.1)$ \\
\hline Depressed mood $(>10)(\%)$ & I,024 (22.I) & $798(25.0)$ & $8(14)$ & $14(16)$ & $48(16.0)$ & $156(15.8)$ \\
\hline
\end{tabular}

Notes: *Number deceased/number total. All data are presented as frequencies (percentage), except for follow-up time, age, and education which are presented as mean (standard deviation). alADL: any difficulty in shopping for groceries, ability to handle finances, mode of transportation, heavy housekeeping, light housekeeping, and ability to use a telephone. 'Mild mobility limitation: any difficulty in squatting, lifting an II kg weight, or running 20-30 m; moderate mobility limitation: any difficulty standing for I5 minutes, walking 200-300 m, or climbing up two to three floors; severe mobility limitation: raising one's arms up or grasping with one's fingers.' cMeasured using the CESD-10 Scale (range: 0-30; cutoff: 10). ${ }^{2}$

Abbreviations: CESD-10, Center for Epidemiologic Studies Depression I0; IADL, instrumental activities of daily living; N, number. 
Table S2 HR and $95 \% \mathrm{Cl}$ of baseline 5-frequency gardening on all-cause mortality and each model mutually adjusted for covariates at baseline

\begin{tabular}{|c|c|c|c|c|c|c|c|}
\hline \multirow{2}{*}{\multicolumn{2}{|c|}{ Model construction }} & \multicolumn{2}{|c|}{ Number } & \multicolumn{4}{|c|}{ HR $(\mathrm{Cl})$ of gardening (reference: nongardener) } \\
\hline & & At risk & Deceased & $<$ I time/month & $2-3 /$ month & I-2/week & Almost daily \\
\hline \multicolumn{2}{|c|}{ Unadjusted model } & 5,043 & I,893 & $0.53(0.32-0.88)$ & $0.66(0.45-0.97)$ & $0.67(0.55-0.83)$ & $0.65(0.57-0.74)$ \\
\hline \multicolumn{2}{|c|}{$\begin{array}{l}\text { Model A: adjusted for age, sex, with } \\
\text { or without a domestic partner }\end{array}$} & 5,043 & $\mathrm{I}, 893$ & $0.52(0.31-0.86)$ & $0.84(0.57-1.23)$ & $0.72(0.59-0.89)$ & $0.67(0.59-0.76)$ \\
\hline \multicolumn{2}{|c|}{$\begin{array}{l}\text { Model B: model A + education, } \\
\text { employment, residence, income satisfaction }\end{array}$} & 4,615 & 1,631 & $0.62(0.36-1.08)$ & $0.95(0.64-1.42)$ & $0.78(0.63-0.97)$ & $0.73(0.64-0.83)$ \\
\hline \multicolumn{2}{|c|}{$\begin{array}{l}\text { Model C: model B + smoking, drinking, } \\
\text { exercising, IADL }\end{array}$} & 4,580 & $\mathrm{I}, 6 \mathrm{II}$ & $0.61(0.35-1.09)$ & $1.02(0.68-1.52)$ & $0.83(0.66-1.03)$ & $0.80(0.70-0.92)$ \\
\hline \multicolumn{2}{|c|}{$\begin{array}{l}\text { Model D: model C + diabetes, stroke, } \\
\text { cancer, lung, heart, kidney disease }\end{array}$} & 4,559 & $\mathrm{I}, 604$ & $0.65(0.37-1.16)$ & $1.03(0.69-1.53)$ & $0.87(0.70-1.08)$ & $0.80(0.70-0.92)$ \\
\hline \multicolumn{2}{|c|}{ Model E: model D + mobility limitations } & 4,551 & 1,600 & $0.61(0.33-1.10)$ & $0.97(0.65-1.45)$ & $0.87(0.70-1.08)$ & $0.83(0.72-0.95)$ \\
\hline \multicolumn{2}{|c|}{ Model F: model E + depression } & $4,50 \mathrm{I}$ & I,578 & $0.6 I(0.34-1.1 I)$ & $0.97(0.65-1.45)$ & $0.87(0.70-1.08)$ & $0.82(0.7 I-0.94)$ \\
\hline \multicolumn{8}{|c|}{ Model G: model D stratified by mobility limitations and depression at baseline: } \\
\hline \multicolumn{8}{|c|}{ Mobility limitations versus depression: } \\
\hline$(-)$ & $(-)$ & 2,359 & 564 & $0.93(0.46-1.90)$ & $0.78(0.37-1.67)$ & $1.07(0.76-1.52)$ & $1.00(0.81-1.23)$ \\
\hline$(+)$ & $(-)$ & $|| 4 \mid$, & 536 & $0.74(0.23-2.33)$ & $1.50(0.88-2.55)$ & $0.81(0.57-1.16)$ & $0.64(0.50-0.82)$ \\
\hline$(-)$ & $(+)^{\mathrm{a}}$ & 324 & 94 & a & a & $0.90(0.33-2.46)$ & $0.80(0.43-1.13)$ \\
\hline$(+)$ & $(+)^{\mathrm{a}}$ & 653 & 377 & a & $0.61(0.19-1.98)$ & $0.61(0.31-1.20)$ & $0.67(0.46-0.97)$ \\
\hline
\end{tabular}

Note: Models A-G were stepwise adjusted for potential confounders. aGroups with a small sample size and invalid HR were deleted. "(+)” indicates yes; “( -$)$ ” indicates no. Abbreviations: $\mathrm{Cl}$, confidence interval; HR, hazard ratio; IADL, instrumental activities of daily living.

Table S3 HR and 95\% Cl of baseline 5-frequency gardening on all-cause mortality a adjusted for time-dependent covariates

\begin{tabular}{|c|c|c|c|c|c|c|c|}
\hline \multirow{2}{*}{\multicolumn{2}{|c|}{ Time-dependent variables }} & \multicolumn{2}{|c|}{ Number } & \multicolumn{4}{|c|}{ HR (CI) of gardening (times per unit; reference: nongardener) } \\
\hline & & At risk & Deceased & $<$ I time/month & $2-3 /$ month & I-2/week & Almost daily \\
\hline \multicolumn{2}{|c|}{ Model T-I: comorbidities } & 4,521 & 1,291 & $0.50(0.25-1.02)$ & $0.94(0.59-1.50)$ & $0.89(0.70-1.13)$ & $0.81(0.69-0.94)$ \\
\hline \multicolumn{2}{|c|}{$\begin{array}{l}\text { Model T-2: comorbidities + mobility } \\
\text { limitations }\end{array}$} & 4,530 & 1,291 & $0.51(0.26-0.99)$ & $0.98(0.61-1.57)$ & $0.89(0.70-1.13)$ & $0.82(0.70-0.96)$ \\
\hline \multicolumn{2}{|c|}{ Model T-3: comorbidities + depression } & 4,571 & 1,084 & $0.53(0.24-1.20)$ & $0.98(0.59-1.61)$ & $0.92(0.71-1.19)$ & $0.85(0.72-1.00)$ \\
\hline \multicolumn{2}{|c|}{$\begin{array}{l}\text { Model T-4: comorbidities } \\
\text { limitations + depression }\end{array}$} & 4,580 & 1,085 & $0.61(0.29-1.29)$ & $1.02(0.62-1.68)$ & $0.92(0.7 I-1.19)$ & $0.87(0.73-1.02)$ \\
\hline \multicolumn{8}{|c|}{ Model T-5: model T-4 stratified by mobility limitations and depression at baseline: } \\
\hline \multicolumn{8}{|c|}{ Mobility limitations versus depression ${ }^{\mathrm{b}}$ : } \\
\hline$(-)$ & $(-)$ & 2,408 & 386 & $0.95(0.38-2.34)$ & $0.95(0.39-2.33)$ & $1.24(0.84-1.84)$ & I.II (0.87-1.72) \\
\hline$(+)$ & $(-)$ & 1,145 & 367 & $0.30(0.04-2.16)$ & $1.22(0.62-2.40)$ & $0.78(0.5 I-1.19)$ & $0.64(0.48-0.87)$ \\
\hline$(-)$ & $(+)^{c}$ & 332 & 63 & c & c & $0.65(0.13-3.15)$ & $0.93(0.46-1.87)$ \\
\hline$(+)$ & $(+)^{c}$ & 658 & 243 & c & $0.79(0.19-3.32)$ & $0.74(0.34-1.62)$ & $0.64(0.39-1.04)$ \\
\hline
\end{tabular}

Notes: ${ }^{\text {AAll }}$ models adjusted for socioeconomic status (age, sex, with or without a domestic partner, education, employment, residence, income satisfaction), health behaviors (smoking, drinking, exercising), and IADL at baseline; and time-dependent comorbidities, mobility limitations, and depression at baseline if not modeled as time-dependent variables. 'According to Model T-4, stratified by baseline mobility limitations and depression. 'Groups with a small sample size and invalid HR were deleted. "(+)" indicates yes; "(-)" indicates no.

Abbreviations: $\mathrm{Cl}$, confidence interval; $\mathrm{HR}$, hazard ratio; IADL, instrumental activities of daily living. 
Table S4 HR and $95 \% \mathrm{Cl}$ of baseline 5-frequency gardening on all-cause mortality among participants who had limited mobility and no depression at baseline $(\mathrm{N}=\mathrm{I}, \mathrm{I45})$

\begin{tabular}{|c|c|c|}
\hline Variables & $\begin{array}{l}\text { HR }(\mathrm{Cl}) \text { : time-dependent } \\
\text { model without adjusting } \\
\text { for cognition }\end{array}$ & $\begin{array}{l}\text { HR (Cl): adjusting } \\
\text { for time-dependent } \\
\text { cognition }\end{array}$ \\
\hline \multicolumn{3}{|l|}{ Baseline variables } \\
\hline \multicolumn{3}{|l|}{ Frequency of gardening (reference: never) } \\
\hline$<$ I time/month & $0.30(0.04-2.16)$ & $0.31(0.04-2.2 I)$ \\
\hline $2-3 /$ month & $1.22(0.62-2.40)$ & $\mathrm{I} .27(0.64-2.5 \mathrm{I})$ \\
\hline I-2/week & $0.78(0.5 \mathrm{I}-\mathrm{I} . \mathrm{I} 2)$ & $0.81(0.53-1.23)$ \\
\hline Almost daily & $0.64(0.48-0.87)$ & $0.64(0.47-0.87)$ \\
\hline \multicolumn{3}{|l|}{ Age (reference: 50-59) } \\
\hline $60-64$ & $1.54(0.85-2.79)$ & $1.46(0.80-2.65)$ \\
\hline $65-69$ & $2.09(1.26-3.48)$ & $1.96(1.18-3.27)$ \\
\hline $70-74$ & $2.57(1.57-4.22)$ & $2.35(1.43-3.86)$ \\
\hline $75-79$ & $4.27(2.58-7.05)$ & $3.94(2.38-6.53)$ \\
\hline$\geq 80$ & $4.55(2.64-7.83)$ & $4.03(2.32-6.98)$ \\
\hline Male (reference: female) & $2.32(1.77-3.03)$ & $2.31(1.76-3.04)$ \\
\hline \multicolumn{3}{|l|}{ Education (reference: $0-5$ years) } \\
\hline $6-12$ & $0.98(0.69-1.39)$ & $1.02(0.72-1.44)$ \\
\hline$>12$ & $0.91(0.53-1.55)$ & $0.97(0.57-1.65)$ \\
\hline Resided in town (reference: in city) & $0.95(0.7 \mathrm{I}-1.27)$ & $0.95(0.7 \mathrm{I}-1.27)$ \\
\hline Resided in countryside (reference: in city) & $1.03(0.80-1.33)$ & $1.00(0.77-1.29)$ \\
\hline Employed & $0.60(0.4 I-0.88)$ & $0.64(0.44-0.93)$ \\
\hline Having a partner & $1.08(0.85-1.38)$ & $1.05(0.83-1.35)$ \\
\hline \multicolumn{3}{|c|}{ Satisfaction with current economic status (reference: mediocre) } \\
\hline Unsatisfied & $1.09(0.77-1.54)$ & $1.10(0.78-1.56)$ \\
\hline Satisfied & $1.02(0.81-1.28)$ & $0.99(0.79-1.25)$ \\
\hline Current smoker & $1.35(1.02-1.77)$ & $1.32(1.00-1.74)$ \\
\hline Current drinker & $0.67(0.48-0.93)$ & $0.68(0.49-0.96)$ \\
\hline \multicolumn{3}{|l|}{ Frequency of exercise (reference: never) } \\
\hline I-5 times/week & $0.92(0.66-1.29)$ & $0.94(0.67-1.32)$ \\
\hline$\geq 6$ times/week & $0.86(0.68-1.09)$ & $0.89(0.70-1.13)$ \\
\hline IADL impaired $(>0)^{\mathrm{a}}$ & $1.16(0.91-1.48)$ & $1.12(0.87-1.43)$ \\
\hline \multicolumn{3}{|l|}{ Time-dependent variables } \\
\hline Diabetes mellitus & $1.57(1.21-2.03)$ & $1.57(1.21-2.04)$ \\
\hline Heart disease & $1.03(0.80-1.31)$ & $1.02(0.80-1.30)$ \\
\hline Stroke & $0.96(0.62-1.49)$ & $0.93(0.59-1.46)$ \\
\hline Cancer & $2.43(1.56-3.80)$ & $2.34(1.49-3.66)$ \\
\hline Lung disease & $1.40(1.05-1.85)$ & $1.38(1.04-1.83)$ \\
\hline Kidney disease & $1.41(0.98-2.05)$ & $1.47(1.01-2.13)$ \\
\hline \multicolumn{3}{|l|}{ Mobility limitation ( reference: no limitation) } \\
\hline Mild & $1.48(0.93-2.36)$ & $1.43(0.89-2.28)$ \\
\hline Moderate & $2.13(1.36-3.33)$ & $2.02(1.29-3.17)$ \\
\hline Severe & $2.86(1.75-4.67)$ & $2.66(1.62-4.36)$ \\
\hline Depressed mood $(>10)^{c}$ & $1.14(0.86-1.51)$ & $1.14(0.86-1.52)$ \\
\hline Poor cognition performance ${ }^{d}$ & Not included in this model & $1.55(1.23-1.97)$ \\
\hline
\end{tabular}

Notes: aIADL: any difficulty in shopping for groceries, ability to handle finances, mode of transportation, heavy housekeeping, light housekeeping, and ability to use a telephone. 'Mild mobility limitation: any difficulty in squatting, lifting an II kg weight, or running 20-30 m; moderate mobility limitation: any difficulty standing for 15 minutes, walking 200-300 m, or climbing up two to three floors; severe mobility limitation: raising one's arms up or grasping with one's fingers.' 'Measured using the CESD-10 Scale (range: 0-30; cutoff: 10) ${ }^{2,3} \mathrm{~d}$ Immediate recall of ten items modified from Rey Auditory Verbal Learning Test, ${ }^{4}$ and of one task from Digits Backward Test. ${ }^{5}$

Abbreviations: CESD-10, Center for Epidemiologic Studies Depression 10; Cl, confidence interval; HR, hazard ratio; IADL, instrumental activities of daily living. 
Table S5 HR and $95 \% \mathrm{Cl}$ of baseline 5-frequency gardening on all-cause mortality adjusted for time-dependent covariates among people with IADL impairments ${ }^{\mathrm{a}}$ in $1996(\mathrm{~N}=1,415)$

\begin{tabular}{|c|c|c|}
\hline Variables & $\begin{array}{l}\mathrm{HR}(\mathrm{Cl}) \text { without } \\
\text { adjusting for cognition }\end{array}$ & $\begin{array}{l}\text { HR }(\mathrm{Cl}) \text { adjusting for } \\
\text { time-dependent cognition }\end{array}$ \\
\hline \multicolumn{3}{|l|}{ Baseline variables } \\
\hline \multicolumn{3}{|l|}{ Frequency of gardening (reference: never) } \\
\hline$<$ I time/month & $0.25(0.04-1.82)$ & $0.26(0.04-1.84)$ \\
\hline $2-3 /$ month & $0.89(0.36-2.20)$ & $0.94(0.38-2.32)$ \\
\hline I-2/week & $0.99(0.67-1.47)$ & $1.04(0.70-1.53)$ \\
\hline Almost daily & $0.58(0.43-0.79)$ & $0.59(0.43-0.80)$ \\
\hline \multicolumn{3}{|l|}{ Age (reference: $50-59$ ) } \\
\hline $60-64$ & $1.32(0.78-2.23)$ & $1.28(0.75-2.17)$ \\
\hline $65-69$ & $1.71(1.10-2.65)$ & $\mathrm{I} .62(\mathrm{I} .04-2.5 \mathrm{I})$ \\
\hline $70-74$ & $1.62(1.06-2.49)$ & $1.53(1.00-2.35)$ \\
\hline $75-79$ & $2.91(1.88-4.50)$ & $2.78(I .79-4.31)$ \\
\hline$\geq 80$ & $3.22(2.06-5.04)$ & $2.94(1.86-4.63)$ \\
\hline Male (reference: female) & $2.60(2.10-3.22)$ & $2.56(2.06-3.19)$ \\
\hline \multicolumn{3}{|l|}{ Education (reference: $0-5$ years) } \\
\hline $6-12$ & $1.06(0.76-1.48)$ & $1.12(0.80-1.58)$ \\
\hline$>12$ & $1.05(0.60-1.83)$ & $1.17(0.67-2.04)$ \\
\hline Resided in town (reference: in city) & $1.20(0.93-1.55)$ & $1.18(0.91-1.53)$ \\
\hline Resided in countryside (reference: in city) & $1.23(0.99-1.54)$ & $1.24(0.99-1.55)$ \\
\hline Employed & $0.61(0.39-0.95)$ & $0.62(0.40-0.98)$ \\
\hline Having a partner & $0.85(0.70-1.04)$ & $0.84(0.69-1.03)$ \\
\hline \multicolumn{3}{|c|}{ Satisfaction with current economic status (reference: mediocre) } \\
\hline Unsatisfied & $0.95(0.75-1.20)$ & $0.94(0.74-1.20)$ \\
\hline Satisfied & $0.97(0.79-1.19)$ & $0.99(0.80-1.22)$ \\
\hline Current smoker & $0.96(0.74-1.23)$ & $0.97(0.75-1.25)$ \\
\hline Current drinker & $0.75(0.53-1.06)$ & $0.75(0.53-1.06)$ \\
\hline \multicolumn{3}{|l|}{ Frequency of exercise (reference: never) } \\
\hline I-5 times/week & $0.75(0.55-1.03)$ & $0.78(0.57-1.07)$ \\
\hline$\geq 6$ times/week & $0.83(0.67-1.02)$ & $0.86(0.70-1.06)$ \\
\hline \multicolumn{3}{|l|}{ Time-dependent variables } \\
\hline Diabetes mellitus & $1.56(1.26-1.94)$ & $1.62(1.29-2.02)$ \\
\hline Heart disease & $1.09(0.89-1.33)$ & $1.08(0.87-1.33)$ \\
\hline Stroke & $0.96(0.69-1.34)$ & $0.95(1.68-1.33)$ \\
\hline Cancer & $2.32(1.51-3.57)$ & $2.41(1.55-3.75)$ \\
\hline Lung disease & $1.39(1.10-1.74)$ & $1.33(1.10-1.75)$ \\
\hline Kidney disease & $1.32(0.98-1.76)$ & $1.28(0.95-1.73)$ \\
\hline \multicolumn{3}{|l|}{ Mobility limitation (reference: no limitation) } \\
\hline Mild & $1.42(0.93-2.19)$ & I.47 (0.94-2.28) \\
\hline Moderate & $2.19(1.48-3.25)$ & $2.25(1.50-3.37)$ \\
\hline Severe & $3.17(2.09-4.80)$ & $3.15(2.05-4.83)$ \\
\hline Depressed mood $(>10)^{c}$ & $1.20(0.98-1.45)$ & $1.19(0.97-1.45)$ \\
\hline Poor cognition performance ${ }^{d}$ & Not included in the model & $1.28(1.05-1.56)$ \\
\hline
\end{tabular}

Notes: aIADL, any difficulty in shopping for groceries, ability to handle finances, mode of transportation, heavy housekeeping, light housekeeping, and ability to use a telephone. bMild mobility limitation, any difficulty in squatting, lifting an II kg weight, or running 20-30 m; moderate mobility limitation, any difficulty standing for 15 minutes, walking 200-300 m, or climbing up two to three floors; severe mobility limitation, raising one's arms up or grasping with one's fingers.' 'Measured using the CESD- 10 Scale (range: 0-30; cutoff: 10). ${ }^{2,3}$ dmmediate recall of ten items modified from Rey Auditory Verbal Learning Test, ${ }^{4}$ and of one task from Digits Backward Test. ${ }^{5}$

Abbreviations: CI, confidence interval; CESD-10, Center for Epidemiologic Studies Depression I0; HR, hazard ratio; IADL, instrumental activities of daily living.

\section{References}

1. Yeh CJ, Wang CY, Tang PF, Lee MC, Lin HS, Chen HY. Hierarchy of higher-level physical functions: a longitudinal investigation on a nationally representative population of community-dwelling middle-aged and elderly persons. Disabil Rehabil. 2012;34(15):1271-1276.

2. Andresen EM, Malmgren JA, Carter WB, Patrick DL. Screening for depression in well older adults: evaluation of a short form of the CES-D (Center for Epidemiologic Studies Depression Scale). Am J Prev Med. 1994;10(2):77-84.
3. Chang KF, Weng LJ. Screening for depressive symptoms among older adults in Taiwan: Cutoff of a short form of the Center for Epidemiologic Studies Depression Scale. Health. 2013;5(3A):588-594.

4. Lezak MD. Neuropsychological assessment. 2nd ed. New York: Oxford University Press; 1983.

5. Matarazzo JD. Wechsler's measurement and appraisal of adult intelligence. 5th ed. Baltimore: Williams \& Wilkins; 1972. 
Clinical Interventions in Aging

\section{Publish your work in this journal}

Clinical Interventions in Aging is an international, peer-reviewed journal focusing on evidence-based reports on the value or lack thereof of treatments intended to prevent or delay the onset of maladaptive correlates of aging in human beings. This journal is indexed on PubMed Central, MedLine,

CAS, Scopus and the Elsevier Bibliographic databases. The manuscript management system is completely online and includes a very quick and fair peer-review system, which is all easy to use. Visit http://www.dovepress. $\mathrm{com} /$ testimonials.php to read real quotes from published authors.

Submit your manuscript here: http://www.dovepress.com/clinical-interventions-in-aging-journal 